\title{
Coagulation Impairment in Type 2 Diabetes Mellitus
}

\author{
Fayeza Karim¹, Qazi Shamima Akter², Shamima Jahan ${ }^{3}$, Afruza Khanom ${ }^{4}$, Samira Haque ${ }^{5}$, Tania \\ yeasmin $^{6}$, Tashfia Siddika ${ }^{7}$, Susmita Sinha $^{8}$
}

\begin{abstract}
Background: Complication of diabetes mellitus (DM) includes coagulation impairment. Hypercoagulable state in patient with DM may accelerate thromboembolic risk for cardiovascular disease (CVD). Objective: To assess Prothrombin Time and Activated Partial Thromboplastin Time in type 2 diabetes mellitus for observing their coagubility status. Methods: This cross sectional study was conducted in the Department of Physiology, Dhaka Medical College, Dhaka from July 2013 to June 2014. One hundred male patients with type 2 diabetes mellitus aged 40-60 years and one hundred age, BMI matched healthy subjects were included as control in this study. Patients were selected from BIRDEM, Dhaka. Prothrombin Time (PT), Activated Partial Thromboplastin Time (APTT) were estimated by auto analyzer. For statistical analysis unpaired student't test was used. Results: In this study PT and APTT were significantly $(\mathrm{P}<0.001)$ lower in diabetes mellitus than those of control group. Conclusion: From this study, it may be concluded that diabetic patients are prone to develop coagulation impairment.
\end{abstract}

Key words: Prothromin time, Activated partial thromboplastin time, cardiovascular disease, diabetes mellitus.

J Bangladesh Soc Physiol. 2015, June; 10(1): 26-29

For Authors Affiliation, see end of text.

http://www.banglajol.info/index.php/JBSP

\section{Introduction}

D iabetes mellitus (DM) is characterized by hyperglycemia accompanied with the biochemical alterations in carbohydrate, protein and lipid metabolism ${ }^{1}$. According to WHO, diagnostic criteria of diabetes mellitus are fasting blood glucose e"7.0 $\mathrm{mmol} / \mathrm{l}$, and 2 hour after glucose $\leq 1.11 \mathrm{mmol} / \mathrm{l}$ and $\mathrm{HbA}_{1 \mathrm{c}} \leq 6.5 \%^{2}$.

Diabetes mellitus is a major global health problem. Prevalence of diabetes in Bangladesh was found $8.3 \%$ in the year of 2011, among them $15.2 \%$ in urban and $8.3 \%$ in rural population ${ }^{3,4}$.

Cardiovascular disease (CVD) is the leading cause of disability and premature mortality in patients

Received January 2015; $\quad$ Accepted June 2015 with diabetes ${ }^{5}$. About $80 \%$ patients with diabetes may die due to thromboembolic $\mathrm{CVD}^{6}$.

Coagulation abnormalities with decreased level of antithrombin III, protein $\mathrm{C}$ and protein $\mathrm{S}$ has been reported in DM with elevated clotting factors ${ }^{7}$. Moreover, there is also increase in plasminogen activator inhibitor type 1 which decreases fibrinolysis. Together they contribute to hypercoagulability state in $\mathrm{DM}^{8}$. Hypercoagulability in diabetes may accelerate atherosclerosis and acts as a risk factor of cardiovascular disease (CVD) ${ }^{9}$. Measurement of prothrombin time (PT), activated partial thromboplastin time (APTT), bleeding time and clotting factor concentration are are usually done 
in patients with a suspected abnormal coagulation. Protrombin time (PT) and APTT are the marker for activation of extrinsic and intrinsic pathway respectively ${ }^{10,11,12}$. The hypercoaguability state demonstrated by shortened PT and APTT in DM may cause occlusive thrombus within a coronary artery ${ }^{13}$. Therefore shortened PT and APTT value is the risk factors for thromboembolic cardiovascular disease in type 2 diabetic patients ${ }^{14}$.

Therefore, this study aimed to investigate the importance of routine determination PT \& APTT in order to assess the coagulation impairment in DM to prevent the thromboembolic CVD.

\section{Methods}

This cross sectional study was done in the department of Physiology in Dhaka Medical College Dhaka in July 2013 to June 2014. Protocol of this study was approved by Ethical review committee of Dhaka Medical College and Diabetic Association of Bangladesh. For this study 100 male, age (40-60 years), type 2 diabetic patients with FBG level $\geq 7.0 \mathrm{mmol} / \mathrm{l}$ and $\mathrm{HbA}_{1} \mathrm{c} \geq 6.5 \%{ }^{2}$ and also duration of diabetes $>3$ years were selected from BIRDEM, Dhaka. All the study subjects were on oral hypoglycemic drugs. One hundred healthy age BMI matched apparently healthy male were considered as control. After selection of the subjects, the nature, purpose and benefit of the study were explained to each subject in details. They were encouraged for voluntary participation. Informed written consent was taken from the participants. Before taking blood, detailed family and medical history were taken. Anthropometric measurement of the subjects was done and blood pressure was measured. All the information were recorded in a prefixed data schedule. With aseptic precaution, $5 \mathrm{ml}$ of venous blood was collected from antecubital vein by a disposable plastic syringe from each subject for estimation of PT and APTT level by auto analyzer in the laboratory of the Immunology Department of BIRDEM, Dhaka. All the parameters were expressed as mean \pm SD. Statistical analysis was done by unpaired Student's 't' test. P value $<0.05$ was accepted as level of significance. Statistical analyses were performed by using a computer based statistical program SPSS (Statistical package for social science) (version 19).

\section{Results}

General characteristics are presented in table I. Subjects of two groups were matched in respect of age. BMI and BP. Mean prothrombin time (PT) and activated partial thromboplastin time (APTT) levels were significantly $(\mathrm{P}<0.001)$ lower in patients with diabetes mellitus (Table II). Again, in this study abnormally shortened PT and APTT were found in 93\% and 91\% diabetic patients respectively (Figure $1 \& 2$ ).

Table I: General characteristics of study subjects $(n=200)$

\begin{tabular}{lcc}
\hline Parameters & $\begin{array}{c}\text { Control } \\
(\mathrm{n}=100)\end{array}$ & $\begin{array}{c}\text { Diabetes } \\
(\mathrm{n}=100)\end{array}$ \\
\hline Age (years) & $53.58 \pm 4.75$ & $54.72 \pm 5.73$ \\
BMI $\left(\mathrm{K} / \mathrm{m}^{2}\right)$ & $23.13 \pm 2.26$ & $23.15 \pm 2.96$ \\
SBP $(\mathrm{mm}$ of $\mathrm{Hg})$ & $110 \pm 7.02$ & $108 \pm 10.20$ \\
DBP $(\mathrm{mm}$ of $\mathrm{Hg})$ & $65.95 \pm 6.34$ & $62.80 \pm 4.40$ \\
\hline
\end{tabular}

Results are expressed as Mean \pm SD. Unpaired Student's ' $t$ ' test analyzed statistical significance. $\mathrm{n}=$ Number of subjects. BMI $=$ Body mass index, $\mathrm{SBP}=$ systolic blood pressure, DBP $=$ Diastolic blood pressure.

Table II: PT and APTT in different groups $(\mathrm{n}=200)$

\begin{tabular}{lcc}
\hline Parameter & $\begin{array}{c}\text { Control } \\
(\mathrm{n}=100)\end{array}$ & $\begin{array}{c}\text { Diabetes } \\
(\mathrm{n}=100)\end{array}$ \\
\hline PT(sec) & $11.18 \pm 0.41$ & $9.54 \pm 0.58 * * *$ \\
APTT (sec) & $31.88 \pm 2.20$ & $19.94 \pm 0.62 * * *$ \\
\hline
\end{tabular}

Results are expressed as Mean \pm SD. Unpaired Student's ' $t$ ' test analyzed statistical significance. ${ }^{* * *} \mathrm{P}<0.001$. $\mathrm{PT}=$ Prothrombin time, APTT=Activated partial thromboplastin time. 


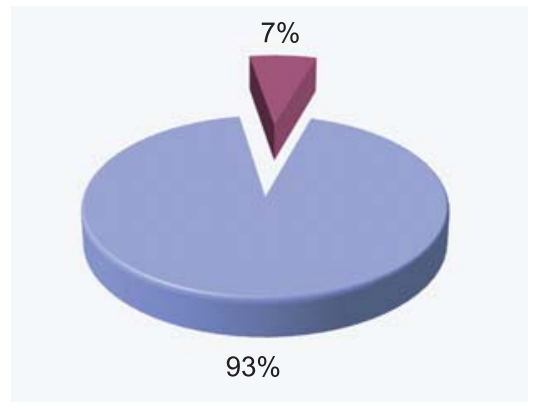

Figure 1: Frequency\% of PT in diabetic patients are showing majority of patients had abnormally low prothrombin time $(\mathrm{n}=100)$ Cut point $=11 \mathrm{sec}$

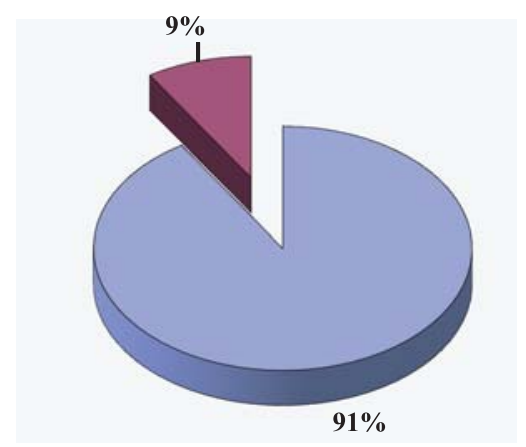

Figure 2: Frequency\% distribution of activated partial thromboplastin time in diabetes is presenting that majority of patients had abnormally lower APTT. $(n=100)$ Cut point $24 \mathrm{sec}$.

\section{Discussion}

In the present study, lower PT level in type 2 diabetic male than healthy male is comparable to others ${ }^{15,16}$. But some studies found no significant changes ${ }^{17,18,19}$, whereas few investigators found prolonged PT in type 2 diabetic subjects ${ }^{20}$.

Again, in the present study, APTT level was lower in type 2 diabetic male which was similar to others ${ }^{21,22}$. But, some investigators did not find any significant change of APTT in between type 2 diabetic male and adult healthy male ${ }^{23,24}$. Moreover, some researcher found that APTT level was prolonged in type 2 diabetic subjects ${ }^{25}$.

It has been suggested that natural anticoagulant antithrombin III keeps the natural procoagulant inhibited. In addition protein C inactivates factors
Va and VIIIa. Hyperglycemia causes non enzymatic glycation of this antithrombin III and depressed it's biological activity and also directly decreases the concentration of protein C. Therefore impaired function of natural anticoagulants activate clotting factors and contribute to the onset of hypercoagulability in $\mathrm{DM}^{26,27}$. In this study the abnormally low levels of PT \& APTT in 93\% \& 91\% in diabetic patients, in addition to significantly lower mean level of these parameters in DM are suggestive of hypercoagulable state in diabetes which may acts as a risk factor for future cardiovascular disease ${ }^{28}$.

\section{Conclusion}

From the present study it may be concluded that patients with diabetes mellitus are more prone to develop hypercoagulation state. Therefore, routine examinations of PT \& APTT are important to assess coagulation impairment in DM in order to prevent thromboembolic CVD in DM.

\section{Acknowledgement}

The authors acknowledge Department of Immunology, BIRDEM, Dhaka, for their cooperation during sample collection and analysis.

\section{Conflict of Interest : None}

\section{Authors Affiliations}

*1. Fayeza Karim, Assistant professor, Department of Physiology, Aichi Medical College, Uttara, Dhaka. Email: drfayeza75@yahoo.com

2. Quzi Shamima Akter. Professor and Head, Department of Physiology, Dhaka medical college, Dhaka.

3. Shamima Jahan, Assistant professor, Department of Physiology, Central Medical College, Comilla.

4. Afruza Khanom, Assistant professor, Department of Physiology, Marks Medical College, Dhaka.

5. Samira Haque, Medical officer, Dhaka medical College, Dhaka.

6. Tania yeasmin, Assistant professor, Department of Physiology, East West Medical College, Uttara, Dhaka.

7. Tashfia Siddika, Lecturer, Department of Physiology, Shaheed Suhrawardi Medical College, Dhaka.

8. Susmita Sinha, Assistant professor, Department of Physiology, Estern Medical College, Comilla.

*For correspondence

J Bangladesh Soc Physiol. 2015, June; 10(1): 26-29 


\section{References}

1. Jabeen F, Rizvi HA, Aziz F, Wasti AZ. Hyperglycemic induced variations in Hematological Indices in Type 2 Diabetics. Int J Adv Res 2013;1(8):322-34.

2. Seino Y, Nanjo K, Tajima N, Kadowaki T, Kashiwagi A, Araki E. Report of the committee on the classification and diagnostic criteria of Diabetes Mellitus. J Diabetes invest. 2010; 1(5): 212-28.

3. Unwin N, Whiting D, Guariguata L, Ghyoot G, Gan D. The IDF Diabetes Atlas. 5th ed. Belgium: De Visu Digital Document Design limited; 2011.

4. Akhter S, Rahman MM, Abe SK, Sultana P. Prevalence of diabetes and pre diabetes and their risk factors among Bangladeshi adults: a nationwide survey. Bull World Health Organization. 2014; 92: 204-13

5. Alao O, Damulak D, Joseph D, Puepet F. Haemostatic Profile of Patients with Type 2 Diabetes Mellitus in Northern Nigeria. Int J Endocrinol 2010;6(1):122-32.

6. Colwell JA, Nesto RW. The Platelet in Diabetes. Diabetes Care 2003;26(7):2181-8.

7. Madan R, Gupta B, Saluja S, Kansr UC, Tripathi BK, Guliani BP. Coagulation Profile in Diabetes and its Association with Diabetic Microvascular Complications. JAPI. 2010;58:481-9.

8. Remkova A. Diagnostic approach of hypercoaguble state. Bratisl lek listy 2006; 107(8): 292-5.

9. Carr ME. Diabetes mellitus: a hypercoagulable state. J Diabetes Complications. 2001; 15(1): 44-54

10. Alzahrani SH, Ajjan RA. Coagulation and fibrinolysis in diabetes. . Diabetes Vasc Dis Res. 2010; 7(4): 260-73.

11. Mwambungu A, Kaile T, Koroloval L, Kwenda J. Marimo C. A screening test for hypercoagulability in type 2 Diabetes Mellitus patients. Asian Acad Res J Multidisciplinary 2013; 1(14): 101-3.

12. Dhule S, Gawali S. Platelet aggregation and clotting time in type 2 diabetic male. Nat J Physiol, Pharm Pharmacol 2014; 4(2): 96-8.

13. Ali SF, Mohammad OW, Elkareem AA, Abdul Aziz MK. Activated partial thromboplastin time in type II Diabetes Mellitus. Al Neelain Med J 2011; 2011: 63-9.

14. Sapkota B, Shrestha SK, Poudel S. Association of activated partial thromboplastin time and fibrinogen level in patients with type II diabetes mellitus. BMC Research Notes. 2013; 6(485): 1-5.

15. Kural A, Seval H, Toker A, Turkal R, Koldas M. Association between fasting plasma glucose and routine coagulation tests. Tip Arastirmalari Dergisi. 2013; 11(3): 99-102.
16. Ayoubi SM. Hemostatic \& fibrinolytic profile in type 2 Diabetes Mellitus: Effect on the Incidence \& severity of Diabetic complications [master thesis]. [Saudi Arabia]: King Saud University; 2009. $75 \mathrm{p}$

17. Acang N, Jalil FD. Hypercoagulation in diabetes mellitus. Southeast Asian J Trop Med Public Health 1993; 24(1): 263-6.

18. Bae SH, Lee J, Roh KH, Kim J. Platelet activation in patient with diabetic retinopathy. Korean J Opthalmol 2003;17:140-4.

19. Matcas H. A Study on the anomalies of hemostasis on a group of dislipoproteinemia patients [master thesis]. [Craiova]: University of Medicine and Pharmacy Craiova; 2009. 139 p.

20. Soltani MM, Dayer MR, Zahed AS, Bahar HA, Nasirbagheban Z. The Buffering role of HDL in balancing the effects of hypercoagulable state in type 2 Diabetes. J Appl Sci 2012; 12(8): 745-52.

21. Rahman YA, Dallatu Mk. Evaluation of prothrombin time and activated partial thromboplastin in patients with diabetes mellitus. Nigerian J Basic Appl Sci 2012; 20(1): 60-3.

22. Zhao Y, Zhang J, Zhang J, Wu J. Diabetes Mellitus is associated with shortened activated partial thromboplastin time and increased fibrinogen values. PLoS ONE. 2011; 6(1): 1-4.

23. Lippi G, Franchini M, Targher G, Montagnana M, Salvagno G, Guidi G, Emmanuel J. Favaloro. Epidemiological association between fasting plasma glucose and shortened APTT. Clin Biochem 2009; 42: $118-20$

24. Ayoubi SM. Hemostatic \& fibrinolytic profile in type 2 Diabetes Mellitus: Effect on the Incidence \& severity of Diabetic complications [master thesis]. [Saudi Arabia]: King Saud University; 2009. $75 \mathrm{p}$

25. Carmassi F, Morale M, Puccetti R, Negri F, Monzani F, Navalesi R. Coagulation and fibrinolytic system impairment in insulin dependent diabetes mellitus. Thromb Res 1992; 67(6): 643-54.

26. Hassan FM. Prothrombin time and activated partial thromboplastin time among type 2 non insulin dependent diabetes mellitus patients. Recent Res Sci Technol 2009; 1(3): 131-3.

27. Ceriello A. Coagulation activation in diabetes mellitus: the role of hyperglycaemia and therapeutic prospects. Diabetologia 1993; 36(11): 1119-25.

28. Erem C, lua AH, Ovalia UC, Ersoza O, Ukinca K, Telatar OD. Coagulation and Fibrinolysis Parameters in Type 2 Diabetic Patients with and without Diabetic Vascular Complications. Med Princ Pract 2005; 14: 22-30.

29. Grant PJ. Diabetes mellitus as a prothrombotic condition. J Inter Med 2007; 262; 157-2. 